\title{
Pulmonary Stenosis due to External Compression by a Pericardial Band
}

\author{
J. L. BARROS AND F. PÉREZ GÓMEZ \\ From the Surgical Department, Provincial Hospital, and the Cardiopulmonary Department, \\ Clinic Hospital, University of Madrid, Spain
}

Extrinsic compression of the outflow tract of the right ventricle by a pericardial band has been described by Mounsey (1959) and later reported by other authors (McGaff et al., 1963; Portal et al., 1966; Weglicki et al., 1965). All, except the case presented by Weglicki et al., were patients who had undergone partial pericardiectomy some years before for constrictive pericarditis.

This report presents a similar case in which surgical resection of the constrictive pericardial band abolished the previous gradient between the right ventricle and pulmonary artery.

\section{Case Report}

A woman aged 21 was first seen in 1960. Partial resection of the pericardium had been performed 6 years before in another hospital for constrictive pericarditis. At first she noticed some improvement, but soon her previous symptoms reappeared: increasing breathlessness on effort, ankle œdema, and ascites.

On examination, there was generalized odema and peripheral cyanosis. The pulse was regular, of small volume, and at a rate of 80 beats a minute. The blood pressure was $95 / 50 \mathrm{~mm}$. $\mathrm{Hg}$. The jugular venous pressure was raised $10 \mathrm{~cm}$. above the sternal angle with deep " $x$ " and " $y$ " waves. Powerful pulsation was felt over the left sternal edge and a systolic thrill over the pulmonary area. On auscultation there was a loud and long systolic murmur at the pulmonary area overriding the aortic second heart sound and a short mid-diastolic murmur at the mitral area. There was dullness on percussion over the base of the right hemithorax. The liver was enlarged and there was ascites. The peripheral pulses were present and the ocular fundi were normal. Routine blood and urine tests were normal.

The electrocardiogram (Fig. 1, left) showed sinus rhythm, right axis deviation, low voltage in the standard limb leads, and gross right ventricular hypertrophy. The $\mathbf{P}$ waves were normal. The phonocardiogram showed a long ejection systolic murmur at the pulmonary area and a mid-diastolic murmur at the mitral area. The pulmonary second sound was not recorded. The chest $x$-ray film (Fig. 2) showed adhesions at the right base, a small aorta, and enlargement of the heart, with its left border bulging upwards and to the left, probably representing dilatation of the right ventricle.

A systolic gradient of $105 \mathrm{~mm}$. $\mathrm{Hg}$ between the right ventricle and pulmonary artery was demonstrated at cardiac catheterization (Fig. 3). The gradient was apparently at pulmonary valve level.

The patient was operated on (J. L. Barros). The heart was approached by a bilateral thoracotomy. A thick fibrotic band of pericardium was found overlying and compressing the outflow tract of the right ventricle at the level of the transverse sinus and twisting the root of the pulmonary artery. The right ventricle was seen to be dilated and pulsating vigorously through the hole in the pericardium made at the previous operation. The pericardium over the left ventricle was fibrosed and thick mainly over the left atrio-ventricular groove. Resection of the whole pericardium was carried out leaving the heart completely free.

Examination post-operatively showed a normal jugular venous pressure and an impalpable right ventricle. On auscultation there was a soft ejection systolic murmur at the pulmonary area. The electrocardiogram (Fig. 1, right) now showed normal axis, partial right bundlebranch block, and non-specific abnormalities of the $T$ waves. Cardiac catheterization repeated 3 weeks and 4 years after the operation (Table) showed normal right-sided pressures and almost complete abolition of the pressure gradient between the right ventricle and pulmonary artery.

The patient has been doing full-time work in a factory for the past 6 years.

\section{Comments}

Localized obstruction of the outflow tract of the right ventricle can be produced by a pericardial band in patients with constrictive pericarditis. Three of the reported cases (McGaff et al., 1963; Mounsey, 1959; Portal et al., 1966) had previous partial pericardiectomy performed some years before. The clinical picture of constrictive pericarditis recurred and the heart was found to pulsate 


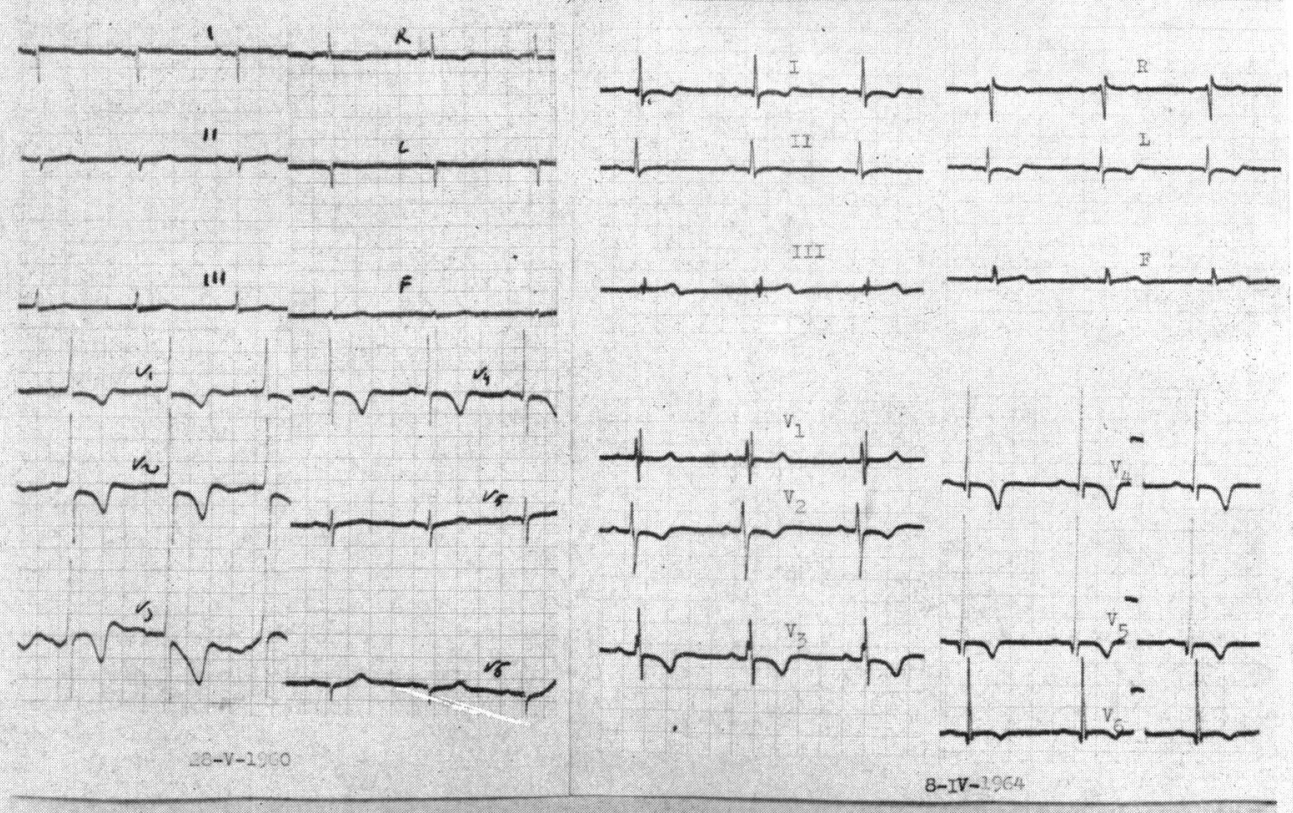

FIG. 1.-The electrocardiogram taken before operation (left) shows low voltage in the limb leads and right ventricular hypertrophy. Four years after operation (right) the graph shows partial right bundle-branch block and non-specific abnormalities of the $T$ wave.

vigorously, with a systolic murmur and thrill at the pulmonary area. When the pericardiectomy is not complete, the pericardium remaining over the outflow tract of the right ventricle may become fibrotic

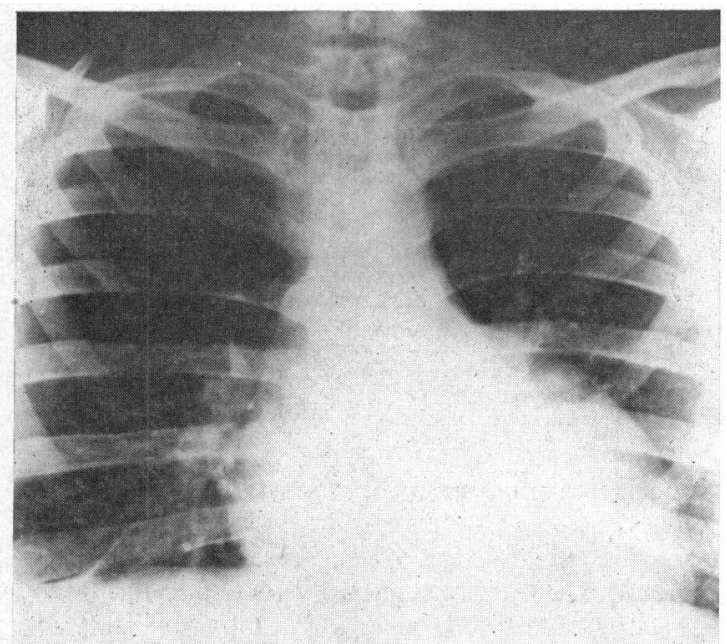

FIG. 2.-Postero-anterior chest film showing right basal adhesions and moderate enlargement of the right ventricle. and produce severe constriction with a pressure gradient between the right ventricle and pulmonary artery. The case described by Weglicki et al. (1965) had a calcified band of pericardium producing obstruction a few centimetres below the pulmonary valve. The patient had not had previous pericardiectomy.

We do not have a clear explanation for the mitral diastolic murmur which is almost invariably found (McGaff et al., 1963; Mounsey, 1959; Portal et al., 1966) and which disappears after resection of the pericardium over the left side of the heart. The wedge pulmonary arterial pressure was normal and there was no evidence of mitral stenosis. Portal et al. (1966) interpret this murmur as evidence of distortion of the atrio-ventricular ring by fibrous pericardium over the left atrio-ventricular groove.

\section{Summary}

We present an unusual case of extrinsic pulmonary stenosis due to a pericardial band in a patient with a partial pericardiectomy performed elsewhere 6 years before for constrictive pericarditis. Cardiac catheterization demonstrated a large pressure gradient between the right ventricle and pulmonary artery, which was practically abolished by the 
TABLE

HEMODYNAMIC RESULTS

\begin{tabular}{|c|c|c|c|c|c|c|}
\hline \multirow[b]{2}{*}{ Date } & \multicolumn{2}{|c|}{ Pulmonary artery } & \multicolumn{2}{|c|}{ Right ventricle } & \multicolumn{2}{|c|}{ Right atrium } \\
\hline & $\begin{array}{c}\text { Systolic/ } \\
\text { diastolic } \\
\text { (mm. Hg) }\end{array}$ & $\underset{(\mathrm{mm} . \mathrm{Hg})}{\text { Mean }}$ & $\begin{array}{c}\text { Systolic/ } \\
\text { diastolic } \\
\text { (mm. Hg) }\end{array}$ & $\begin{array}{c}\text { End } \\
\text { diastolic } \\
(\mathrm{mm} . \mathrm{Hg})\end{array}$ & & Mean \\
\hline May 30, 1960 & $10 / 3$ & 5 & $115 / 0$ & 5 & $\begin{array}{l}a=8 \\
x=7 \cdot 5 \\
v=9 \\
y=5\end{array}$ & 7 \\
\hline June 22,1960 & $25 / 10$ & 17 & $44 / 0$ & - & $\begin{array}{l}a=5 \\
x=1 \\
v=6 \\
y=0\end{array}$ & 3 \\
\hline April 8, 1964 & $28 / 8$ & 20 & $35 /-4$ & 7 & $\begin{array}{l}a=14 \\
x=7 \\
v=15 \\
y=3\end{array}$ & 6 \\
\hline
\end{tabular}

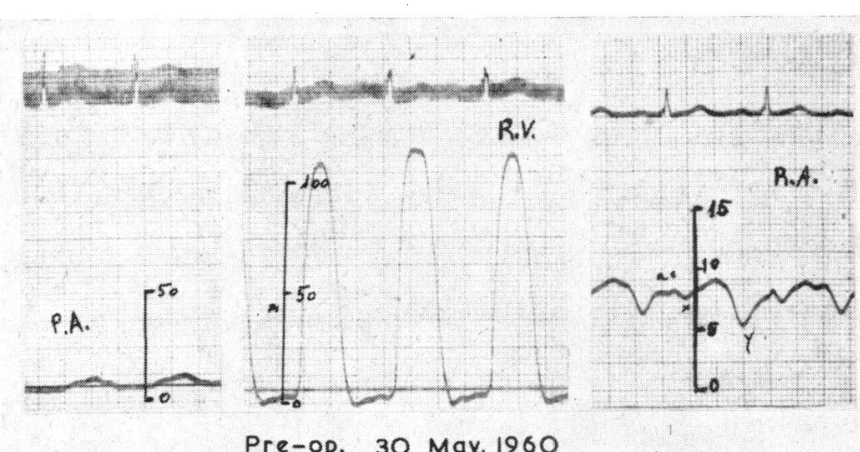

Pre-op. 30 May, 1960
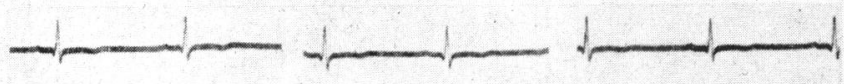

50

50
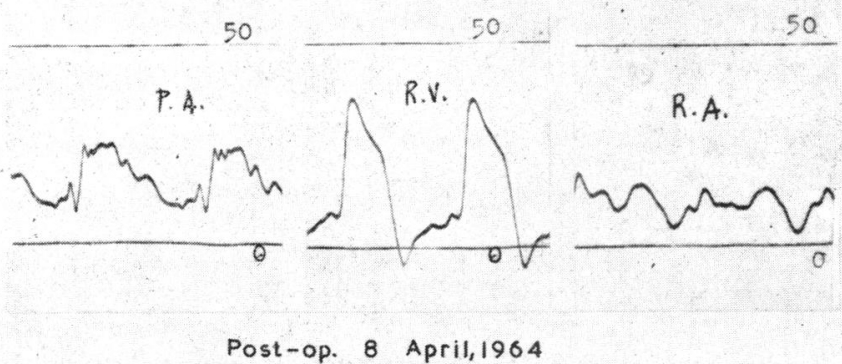

FIG. 3.-Upper half: Pre-operative pressure tracings from the pulmonary artery (PA), right ventricle (RV), and right atrium (RA). A systolic gradient between the right ventricle and pulmonary artery is demonstrated.

Below: Post-operative tracings showing almost complete abolition of the pressure gradient.

second operation. The patient made a complete recovery and has been doing full-time work for the past 6 years.

\section{References}

McGaff, C. J., Haller, J. A., Leight, L., and Towery, B. T. (1963). Subvalvular pulmonary stenosis due to constriction of the right ventricular outflow tract by a pericardial band. Amer. F. Med., 34, 142.
Mounsey, P. (1959). Annular constrictive pericarditis. With an account of a patient with functional pulmonary, mitral, and aortic stenosis. Brit. Heart f., 21, 325.

Portal, R. W., Besterman, E. M. M., Chambers, R. J., Sellors, T. H., and Somerville, W. (1966). Prognosis after operation for constrictive pericarditis. Brit. med. 7., $1,563$.

Weglicki, W. B., Lee, J. F., Brown, I. W., and Whalen, R. E. (1965). Infundibular pulmonic stenosis due to a pericardial band. Amer. F. Cardiol., 16, 262. 